\title{
Does the application of silvicultural management models drive the growth and stem quality of sweet chestnut coppices towards sustainability?
}

\author{
Maria Sameiro Patrício ${ }^{1}$ [D $\cdot$ Luís Nunes $^{1} \cdot$ Maria Loreto Monteiro $^{1}$
}

Received: 10 May 2019 / Accepted: 12 September 2019

(c) Springer Nature B.V. 2019

\begin{abstract}
The coppice is a very flexible cultural system producing several calibers adapting to the demands of the market. Small-caliber roundwood from sweet chestnut (Castanea sativa Mill.) coppices, formerly in great demand, is now less interesting for the market. Thus, the improvement of coppices management by applying alternative silvicultural models in order to obtain benefits and sustainability is essential. For this purpose, four permanent plots (P1-P4) were established in 1994 to monitor different coppice management systems. The plots were installed in a coppice which resulted from the final clear cut of a sweet chestnut high-forest stand in 1992, at 50 years old. Three silvicultural management models were tested in order to produce roundwood of small (P1), medium (P2), and large (P4) diameters. A control plot was established without any type of silviculture which corresponds to most of the existing chestnut coppices $(\mathrm{P} 3=$ without intervention). Thinnings were applied in the plots according to the respective management model. Twenty-four years after the sprouting of the coppice, the silvicultural models were evaluated according to their objectives in terms of growth, yield, and quality of the sawlogs. This assessment period corresponds to the end of the rotation period for $\mathrm{P} 1$, and the results are in accordance with expected values. In P2 and P4 the observed growth closely matches expectations for this growth stage of the coppice. The quality of the sawlogs is clearly superior to that of the plot without intervention. Comparing the mean dendrometric values, higher values were observed in plots where the models were applied. The results also show that when roundwood is used for saw-timber, silvicultural management is essential.
\end{abstract}

Keywords Castanea sativa Mill. · Silviculture · Volume equations · Chestnut coppice · Timber production $\cdot \mathrm{H}-\mathrm{D}$ equations

Maria Sameiro Patrício

sampat@ipb.pt

1 Centro de Investigação de Montanha (CIMO), Instituto Politécnico de Bragança, Campus de Santa Apolónia, 5300-253 Bragança, Portugal 


\section{Introduction}

The sweet chestnut (Castanea sativa Mill.) is one of the most important broadleaf Mediterranean species that can be found either in natural or semi-natural forests accompanied by other plant and animal species, or forming traditional orchards often with centennial trees. In the areas where it is present, the coppice always appears associated with the man who influenced its propagation and use throughout the centuries. Traditionally, chestnut woodlands have fulfilled four fundamental functions: economic (fruit, wood, wood-based products and other non-timber forest products associated to multipurpose forests, such as mushroom production and beekeeping, being a real support of the mountain economy); ecological (ecosystems rich in biodiversity (Fuller and Moreton 1987) and peculiar landscapes, protects against erosion, creates discontinuities in the landscape interposing natural barriers to the progression of wildfires); social (important in the mountain economy, it plays a central role in rural development, boosting the local economy by promoting and enhancing mountain products and setting people); cultural (it has a symbolic value linked to history and tradition with centennial trees contributing to the imagery and revivalism of cultural activities, boosting the tourist activity of mountain regions).

In Portugal, the species covers an area larger than 40,000 hectares (ha) (ICNF 2013), including both orchards and forest woodlands (high-forest and coppice), but young plantations and small woodlands are poorly sampled. The species is mostly found in the north of the country. It is estimated that at least 10 percent of this area corresponds to the surface occupied by sweet chestnut coppices (Patrício 1996; Monteiro and Patrício 1996).

Erstwhile, the coppices of this species played a major role in the production of smallcaliber roundwood mainly for poles, basketry, casks and other utensils used in agriculture, namely in the cultivation of vineyards and wine production. Nowadays, extensive areas of healthy coppices are unmanaged or managed without technical or economic purpose, and are sometimes abandoned since the market does not have a preference for chestnut stems of small diameters. Their use for bioenergy does not seem to be an option for landowners due to high harvest costs and low market prices. Thus, in general, the stands of sweet chestnut coppice are aged and unmanaged, with the consequent degradation of the quality of the sawlogs and the vigor of the trees. Indeed, complete abandonment produces dysfunction at different levels such as bio-geochemical cycles, biological diversity, and landscape patterns (Romane and Houssard 1995).

The demand for high-quality timber of broadleaf species has been increasing over time. High-quality chestnut timber is rare in Portugal but has a long tradition and market preference when available. Thus, the future of chestnut coppices goes through the improvement of management that will lead to increase the caliber and quality of sawlogs, providing greater added-value for the mountain economy. The way forward is to test new silvicultural management models based on the extent of rotation and periodical thinning, adapted to our edaphoclimatic conditions, and to demonstrate to landowners that profit from the coppices can be improved through their reconversion for more valuable roundwood production and multipurpose forestry. In addition, the use of the biomass residues from forest management for bioenergy is a form of complementary income for the owners and reduction of biotic and abiotic risks. Otherwise, a differentiation of management options is needed as an alternative to traditional practices (or lack thereof). This line of thinking has been advocated by other authors (Bourgeois 1987; Amorini and Manetti 2000; Cutini 2001). This type of forest management, based on medium-long rotations towards wood quality is considered also 
more environmentally sustainable. In fact, maximizing the proportion of harvested wood that goes into long lived products, and using only the remainder for bioenergy will increase GHG emissions mitigation benefits (Birdsey et al. 2018).

Considering that silvicultural management of coppices presents great flexibility, the choice of the production objective should result from a compromise between the best technical option to improve the stumpage value, according to the productive potential of the site, and the best economic option. So that we can produce coppice roundwood with several objectives: small diameters, medium diameters, and large diameters, we need to apply reference silvicultural models as those proposed by Bourgeois (1992) and Bourgeois et al. (2004). The suitability of these models to the Portuguese conditions has been tested since 1994 in permanent plots of sweet chestnut coppices. The main aim of this study is to evaluate 24 years of application/adaptation of these silvicultural management models in the north of Portugal compared to a traditional coppice system and to propose new management options which are more sustainable. At the same time, management support tools are developed to monitor the growth and yield trends related to the applied silvicultural management models. These fitted equations, suitable to the juvenile phase and first stages of maturity of chestnut coppices, will be available and can be used by forest managers to monitor height, growth, and yield, either in the form of the stem total volume or up to a top diameter or merchantable height, and thus predict the potential stumpage value to be obtained.

\section{Materials and methods}

\section{Data}

Data on the growth of a sweet chestnut coppice located in Serra da Padrela $\left(41^{\circ} 30^{\prime} 37^{\prime \prime} \mathrm{N}\right.$; $7^{\circ} 37^{\prime} 06^{\prime \prime} \mathrm{W} ; 850$ m.a.s.1.), Northeast of Portugal, was collected for 24 years. The mean annual temperature is $12.5{ }^{\circ} \mathrm{C}$ and the mean annual precipitation is $1132 \mathrm{~mm}$ (INMG 1991). The soil in the stand has developed over metamorphic rocks (schist).

In 1994, through the framework of the research project MEDCOP-AIR 2-CT94-0905, financed by the European Union, four permanent research plots, with an area of about $1000 \mathrm{~m}^{2}$ each, were randomly established in an even-aged sweet chestnut coppice with 2 year old shoots. This coppice was formed after the clear-cutting for timber harvesting of a 50 year-old high-forest sweet chestnut stand $\mathrm{SI}_{45}=24 \mathrm{~m}$ estimated using the equation referred in Patrício and Nunes (2017). Three silvicultural management models, based on Bourgeois (1992), were applied and adapted to our site conditions over time (Table 1). The plots were submitted to the following management models: Plot $1(\mathrm{P} 1)=$ Model - small diameters $(\mathrm{d}<25 \mathrm{~cm})$; Plot $2(\mathrm{P} 2)=$ Model—medium diameters $(25 \mathrm{~cm}<\mathrm{d}<35 \mathrm{~cm})$; Plot $3(\mathrm{P} 3)=$ Control: without intervention; Plot $4(\mathrm{P} 4)=$ Model-large diameters $(\mathrm{d} \geq 40 \mathrm{~cm})$. The plots P1, P2, and P4 were submitted to: a first thinning in 1999 (at 7 years old); a second thinning, that was also the last thinning for P1 and P2, in 2003 (at 11 years old); a third thinning applied only on P4 (large diameters) in 2008 (at 16 years old). The shoots selection was carried out according to the qualitative criteria of stems for timber and vigor. For the final clear cut, using this procedure, we are selecting shoots that present well-formed stems and making available logs with commercial dimensions easily saleable (Patrício et al. 2005). The trial has been evaluated over time (Patrício et al. 2005, 2009; Geraldes 2011; Iamshchikov 2017). 


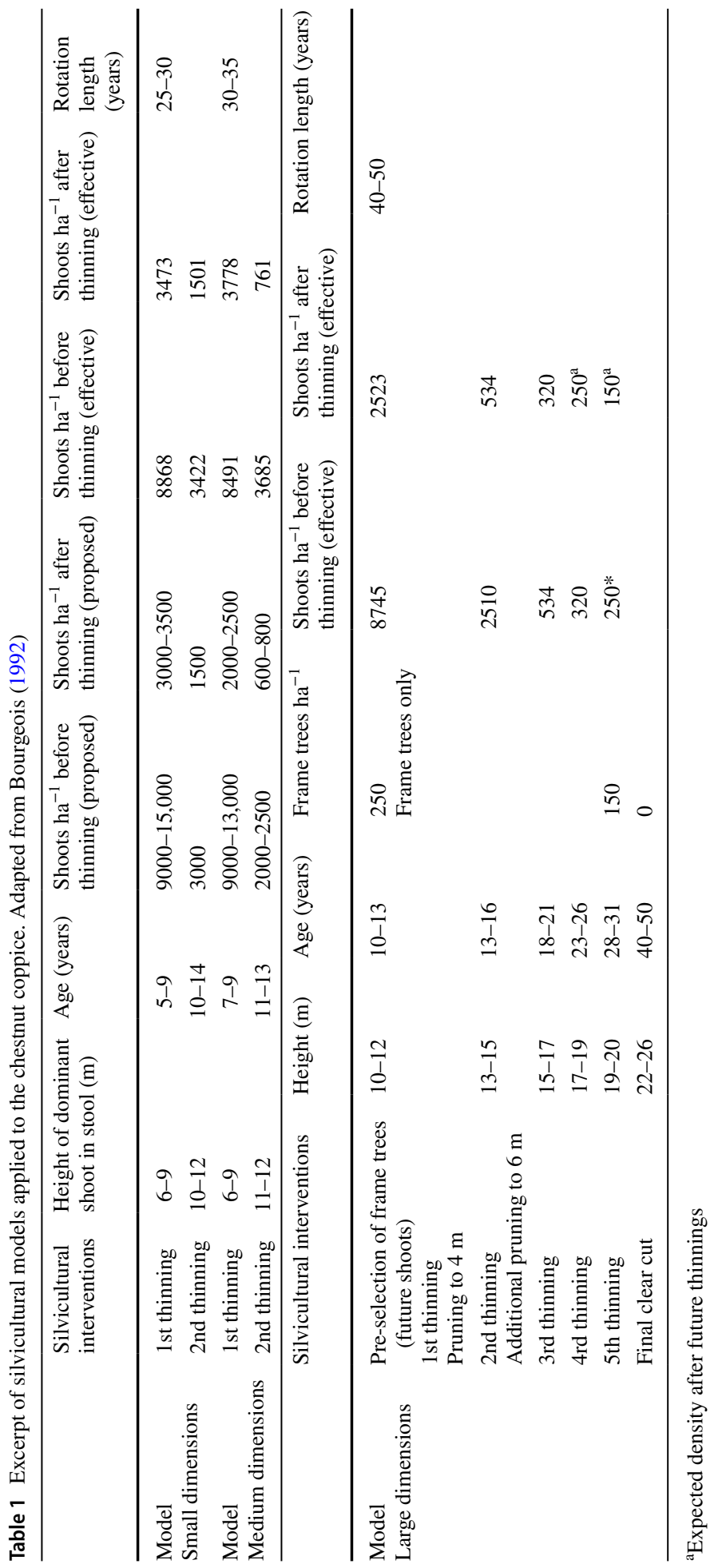


At 24 years old the plots were measured and reassessed. Total height (h), diameter at breast height (d) and live crown height were measured for all shoots in each plot and the number of dead stools and shoots were registered. The dominant height of each plot (hdom) was computed as the average height of the 100 thickest shoots per hectare (Assmann 1970). The dominant diameter (ddom) corresponds to the mean of the diameters (d) of the 100 thickest shoots per hectare. Mean height (hg) was computed as the height of the shoot with the mean basal area (cross-sectional area) in the plot. The $d g$ corresponds to the quadratic mean diameter and is defined as the diameter of the shoot of the mean basal area. The $g$ is the basal area of the shoots calculated as $g=\pi / 4\left(d^{2}\right)$ and $G$ is the basal area per hectare. The average stability coefficient of the shoots was computed dividing the total height by the diameter at breast height $(\mathrm{h} / \mathrm{d})$. The density was evaluated by the number of stools per hectare $\left(\mathrm{Nst} \mathrm{ha}^{-1}\right)$ and shoots per hectare $\left(\mathrm{Nsh} \mathrm{ha}^{-1}\right)$. The survival was assessed by the computation of the percentage of survived stools (\%Survst) and the percent of survived shoots (\%Survsh). The living crown ratio per plot (CR) corresponds to the mean percentage of live crown.

P1 has already achieved the end of rotation (inferior boundary) for the production of small diameter roundwood (mean diameter $14-25 \mathrm{~cm}$ at $25-30$ years). The evaluation of the remaining plots is still ongoing. Only P4 will continue to be thinned based on the silvicultural model for the production of logs with larger diameters $(\mathrm{d} \geq 40 \mathrm{~cm}$ at $40-50$ years old).

\section{Construction of management tools}

\section{Total and percentage volume equations}

Equations to predict the total volume of stems, without stump, as a function of $d$ and $h$ were fitted and evaluated (Table 2). We selected usual equations that were also tested by Patrício (2006) in chestnut's high-forest production system.

The dataset used contained volumes measured in 350 individual stems (shoots) that were removed by thinning in 2003 and 2008. The volume of a cone was assumed for tips and the Smalian formula was used for the rest of the stem when computing the total volume. Summary statistics are presented in Table 3.

Equations were fitted by weighted linear or nonlinear regression in $\mathrm{R}$ software, version 3.5.1 (R Core Team 2018) using the functions $l m$ and $n l s$, respectively. After testing several weights, a weight (w) of $1 /(d h)^{3}$ was adopted to correct for heteroscedasticity. The Huber's

Table 2 Candidate equations to estimate stem total volume

\begin{tabular}{llll}
\hline Designation & Equation & References & Observation \\
\hline EVT1 & $\mathrm{v}=\beta_{0}+\beta_{1} \mathrm{~d}^{2} \mathrm{~h}$ & Spurr (1952) & Linear \\
EVT2 & $\mathrm{v}=\beta_{1} \mathrm{~d}^{2} \mathrm{~h}$ & Spurr (1952) & \\
EVT3 & $\mathrm{v}=\mathrm{d}^{2}\left(\beta_{1}+\beta_{2} \mathrm{~h}\right)$ & Ogaya (1968) & \\
EVT4 & $\mathrm{v}=\beta_{1} \mathrm{~d}^{\beta 2} \mathrm{~h}^{\beta 3}$ & Schumacher and & Nonlinear \\
& & Hall (1933) & \\
EVT5 & $\mathrm{v}=\beta_{1}\left(\mathrm{~d}^{2} \mathrm{~h}\right)^{\beta 2}$ & Spurr (1952) & \\
EVT6 & $\mathrm{v}=\mathrm{d}^{2} /\left(\beta_{0}+\beta_{1} \mathrm{~h}^{-1}\right)$ & Honer (1965) & \\
\hline
\end{tabular}


Table 3 Summary statistics of the total volume dataset

\begin{tabular}{lccr}
\hline Statistic & $\mathrm{v}\left(\mathrm{m}^{3}\right)$ & $\mathrm{d}(\mathrm{cm})$ & $\mathrm{h}(\mathrm{m})$ \\
\hline Maximum & 0.297 & 19.7 & 16.1 \\
Minimum & 0.002 & 2.4 & 4.7 \\
Mean & 0.043 & 9.3 & 10.4 \\
SD & 0.039 & 3.2 & 2.0 \\
\hline
\end{tabular}

influence function (Huber 1964) was used to reduce the influence of data points presenting high fitting errors (“outliers") (Myers 1986, p. 203):

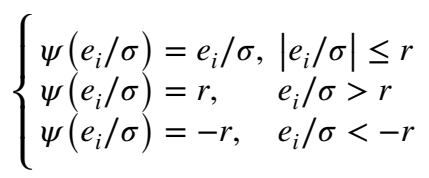

where $e_{i} / \sigma$ are the studentized residuals and $r$ is a limit factor. In our case, if absolute values of studentized residuals (rstud) exceeded $1(\mathrm{r}=1)$, then weights (hereafter called Huber weights and denoted as $\mathrm{Hw}$ ) were equal to 1/absolute(rstud) and equal to 1 otherwise. Huber weights were used together with $w$. They were applied as $H w^{*} w$ in the argument weights of function $\mathrm{lm}$ (or $n l s$ ) call.

Percentage volume equations are useful together with a total volume equation. These equations estimate the percentage of total volume as the ratio $(\mathrm{R})$ of the volume accumulating up to a merchantable diameter (di) or merchantable height (hi) to total volume. They are restricted in order that when $d i=0$ or $h i=h$, R should be equal to 1 for compatibility with total volume equations.

Equations from the work of Patrício (2006) were also tested, especially those with easy application in real practice (Table 4). The dataset used was basically the same for total volume equations except that an expansion was necessary to properly contain the available information about the pairs $d i, h i$ for each tree (total number of observations $=1369$ ).

All of the equations were fitted in R software, version 3.5.1 (R Core Team 2018) with the function $n l s$. The Huber function was used with a limit factor $r=1$. Huber weights computed the same way as explained before were used in the argument weights of function $n l s$ (weights $=\mathrm{Hw})$.

\section{Generalized H-D equation}

To study the height-growth trend of the chestnut coppice under management a generalized $\mathrm{H}-\mathrm{D}$ equation was fitted. To obtain this generalized hypsometric equation common functions were tested. After some preliminary analysis, the candidate equations with the best performance are presented in Table 5.

EHG1 is an adaptation of the Prodan equation modified by Tomé (1988). EHG2 is an adaptation of the Michailoff equation modified by Tomé (1988). EHG3 is from Harrison et al. (1986), EHG4 and EHG5 are also adaptations of the Michailoff equation modified by Tomé (1988).

The dataset contained $2729 h-d$ pairs that were available from measurements of 1999 , 2003, 2008, and 2016 in all plots. The equations were fitted in R software, version 3.5.1 ( $\mathrm{R}$ Core Team 2018) with the function $n l s$. 


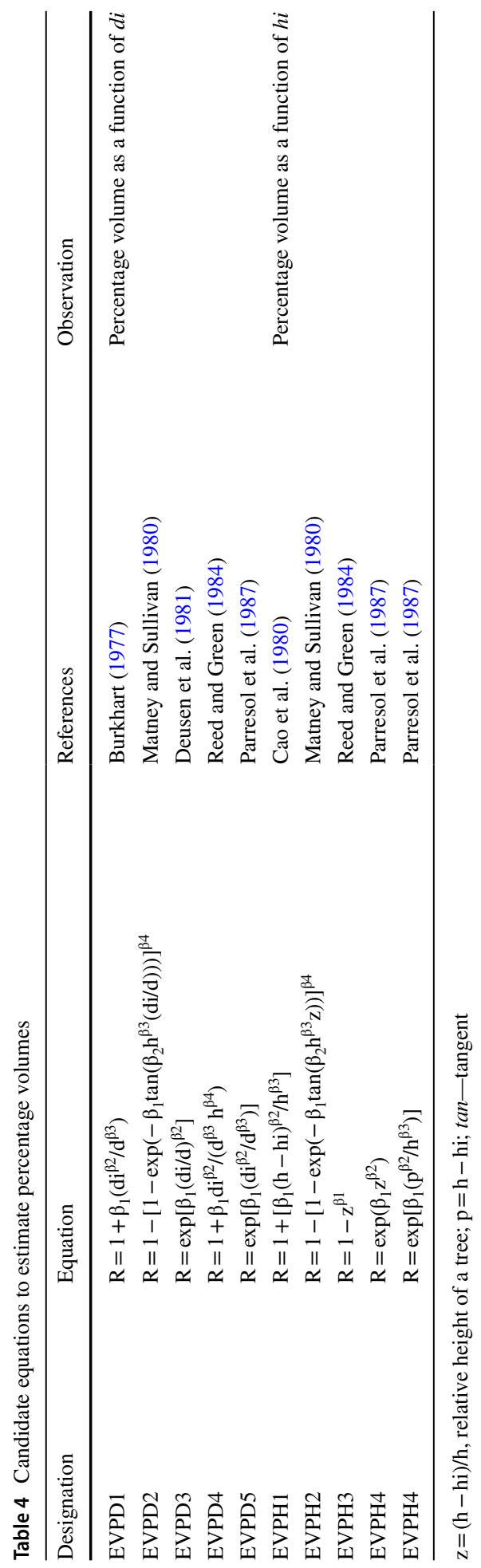


Table 5 Candidate generalized H-D equations to estimate individual height

\begin{tabular}{llll}
\hline Designation & Equation & Age & Parms. \\
\hline EHG1 & $\mathrm{h}=1.3+($ hdom -1.3$)\left(1+\left(\mathrm{b}_{1} \text { hdom }\right)((1 / \mathrm{d})-(1 / \mathrm{ddom}))\right)^{-1}$ & No & 1 \\
EHG2 & $\mathrm{h}=1.3+($ hdom -1.3$) \exp \left(\left(\mathrm{b}_{0}+\mathrm{b}_{1} \mathrm{hdom}+\mathrm{b}_{2}(\mathrm{Nsh} / 1000)\right)((1 / \mathrm{d})-(1 / \mathrm{ddom}))\right)$ & No & 3 \\
EHG3 & $\mathrm{h}=$ hdom $\left(1+\mathrm{b}_{0} \exp \left(\mathrm{b}_{1} \mathrm{hdom}\right)\right)\left(1-\exp \left(-\mathrm{b}_{2} \mathrm{~d} / \mathrm{hdom}\right)\right)$ & No & 3 \\
EHG4 & $\mathrm{h}=1.3+($ hdom -1.3$) \exp \left(\left(\mathrm{b}_{0}+\mathrm{b}_{1}(\mathrm{Nsh} / 1000)+\mathrm{b}_{2} \mathrm{t}\right)((1 / \mathrm{d})-(1 / \mathrm{ddom}))\right)$ & Yes & 3 \\
EHG5 & $\mathrm{h}=1.3+($ hdom -1.3$) \exp \left(\left(\mathrm{b}_{0}+\mathrm{b}_{1} \mathrm{hdom}+\mathrm{b}_{2} \mathrm{dg}+\mathrm{b}_{3} \mathrm{t}\right)((1 / \mathrm{d})-(1 / \mathrm{ddom}))\right)$ & Yes & 4 \\
\hline
\end{tabular}

To compare candidate models, the goodness of fit was assessed with usual statistics such as the adjusted coefficient of determination (R2adj), the root mean square error (RMSE) and quadratic total error (QTE), which is the squared bias plus variance of residuals. Akaike Information Criterion (AIC) was also computed using the formula $n \ln (R S S / n)+2 k$ ( $n$ is the number of observations in the data, RSS is the residuals sum of squares and $k$ is the number of parameters to be estimated). Predictive capacity was evaluated using the residuals obtained with one observation deleted (leave-one-out method), also known as Press residuals. The mean (MPress), the absolute mean (MAPress), the total sum of squares (Press) and the R squared (R2Press) were calculated. This was done for volume and generalized H-D equations.

\section{Results and discussion}

Table 6 shows the dendrometric evaluation of the plots after thinning at 11 years old. Patrício et al. (2005) reported the silvicultural management applied to the plots up to 11 years old. Analyzing Table 6, P1 (Model-small diameters) presented a $d g$ of about $17 \mathrm{~cm}$ and $h g$ of $13 \mathrm{~m}$ as well as ddom $23 \mathrm{~cm}$, and hdom $15 \mathrm{~m}$, being in accordance with the expected values (mean diameter 14-25 cm at 25-30 years) given by the reference models (Bourgeois 1992; Bourgeois et al. 2004). This plot is on the inferior boundary of its rotation period.

The basal area observed in P1 (G $\left.30.4 \mathrm{~m}^{2} \mathrm{ha}^{-1}\right)$ is similar to P3 (G $\left.30.9 \mathrm{~m}^{2} \mathrm{ha}^{-1}\right)$ however only with a $d g$ of $14.5 \mathrm{~cm}$. The sweet chestnut coppice toward higher stumpage value passes through straighter and more cylindrical stems as well as greater individual diameters. Silvicultural intervention favors these aspects by providing stems of better quality and larger diameters as well as greater stand stability (lower stability coefficients $\mathrm{h} / \mathrm{d}$ ).

Since the last thinning we observed a 4 percent mortality in stools and 7 percent in shoots in P1 while in P3, the plot without intervention, intense competition led to a reduction of 27 percent in the number of stools and 68 percent in the number of shoots in relation to the existing density at 11 years old. In P3 the natural reduction in the number of shoots over time tends to that imposed to P1 by thinning. However, competition does not always favor the best shoots for sawlogs. The strong competition observed in P3 also manifests itself in the elimination of stools, not only over shoots. In P2 and P4, no mortality was observed. It should be noted that P4 survival percentage shown in Table $6(60 \%)$ is attributed only to thinning that occurred at age 16. Only P4 was thinned after age 11 following the management model prescriptions for large diameters.

In P2 and P4 (models for medium and large diameters respectively) the observed growth closely follows the expectation for this growth stage of the coppice. P4 has both the best average values for height and diameter and excellent indicators for stability and crown ratio. 


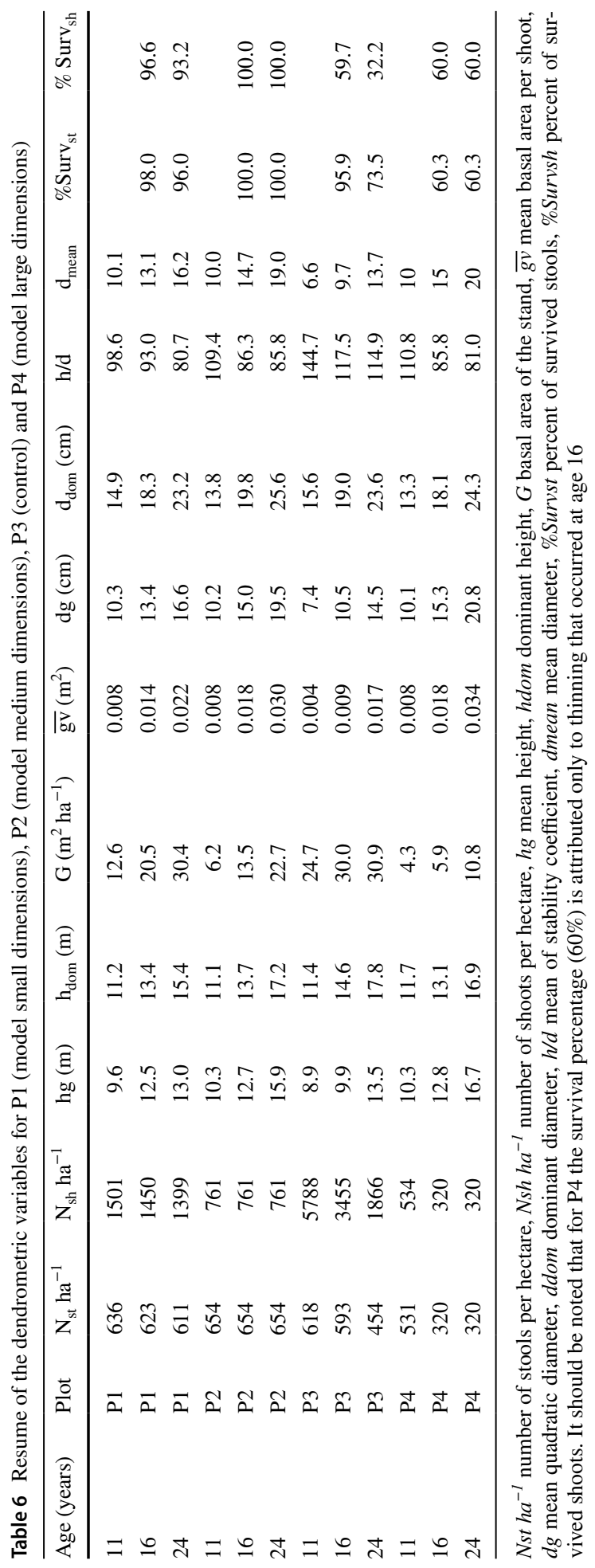


The relationship between silvicultural management and the quality of sawlogs was analyzed in the plots at 16 years old. The study carried out by Patrício et al. (2009) and Geraldes (2011), compared the stem quality of shoots for saw-timber between plots based on qualitative criteria. The used criteria were: the stratification of the canopy from Kraft's Classes (Kraft 1884) (in Assmann 1961), the stem form (cylindricity, curvature, curvature in the base of insertion of the shoot on the stool, insertion height of medium and thick branches on the stem), the first sawlog quality as a whole $(2.25 \mathrm{~m})$ and second $\log$ of 2.25 long (up to $4.50 \mathrm{~m}$ ). Ranks from 1 to 5 were used for each parameter (1 corresponding to the worst and 5 to the best). The results of the multivariate analysis performed, namely principal component analysis (PCA) and redundancy analysis (RDA), showed that the best stem quality for timber of the shoots was associated to P2 and P4. The control without intervention was associated with a stratified canopy due to high competition between shoots in P3. The quality of shoot stems for saw-timber is worse in the control (P3) in comparison to the others. These results demonstrate that the quality of sawlogs is better and more valuable when the silvicultural management models are applied (ibidem). Therefore, the silvicultural management models tested improve the stumpage value contributing to the sustainability of sweet chestnut coppices.

The equation developed for the NW of Spain (Menéndez-Miguélez et al. 2015, 2016) was used to define the site quality since in Portugal SI equations are yet not available for chestnut coppice. Estimated average site quality was $S I_{20}=15 \mathrm{~m}$. Comparing with de site index curves of Duplat presented in Bourgeois et al. (2004), our SI ranges from about $15-17 \mathrm{~m}$ for the same reference age.

The yield at age 24 estimated with EVT1 equation (presented in the next section) was: $194.3 \mathrm{~m}^{3} \mathrm{ha}^{-1}$ for P1, $178.8 \mathrm{~m}^{3} \mathrm{ha}^{-1}$ for P2; $243.3 \mathrm{~m}^{3} \mathrm{ha}^{-1}$ for P3 and $84.9 \mathrm{~m}^{3} \mathrm{ha}^{-1}$ for P4. These values were converted into biomass using the specific gravity value $0.547 \mathrm{~g} \mathrm{~cm}^{-3}$ (Luís and Monteiro 1998). Thus, the long-term carbon retention potential that could be converted into long-life products for the main stand of the managed plots was as follow: 53.2 $\mathrm{Mg} \mathrm{C}^{-1}$ for $\mathrm{P} 1,48.9 \mathrm{Mg} \mathrm{C}^{-1}$ for $\mathrm{P} 2$ and $23.3 \mathrm{Mg} \mathrm{C} \mathrm{ha}^{-1}$ for P4 (using a 0.5 conversion factor). All these values will increase towards the end of the rotation. The potential forest residues from thinning that could be directed to bioenergy were: $59.4 \mathrm{Mg} \mathrm{ha}^{-1}$, 86.2 $\mathrm{Mg} \mathrm{ha}^{-1}, 98.3 \mathrm{Mg} \mathrm{ha}^{-1}$, corresponding to the implemented management in P1, P2 and $\mathrm{P} 4$. Areas of coppice without intervention currently have as their main aptitude ecosystem services and biomass production. So, the biomass potential production of these chestnut coppices, P3 equivalent (without intervention), was $15.5 \mathrm{Mg} \mathrm{ha}^{-1}$ from self-thinning and 133.1 $\mathrm{Mg} \mathrm{ha}^{-1}$ from the main stand, totaling $148.6 \mathrm{Mg} \mathrm{ha}^{-1}$.

According to stand density management diagram (SDMD) (Menéndez-Miguélez et al. 2016), the estimated relative space indexes (RSI) for our plots are: $\mathrm{P} 1=18 \%$; $\mathrm{P} 2=24 \%$; $\mathrm{P} 3=14 \%$ and $\mathrm{P} 4=32 \%$. Thus, management options for medium and large diameters presuppose to maintain $R S I$ between 24 and $32 \%$. These values are in accordance with forestry practiced in France (RSI 20-32\%) for the same purposes for the best site qualities. Plot P1 and mainly P3 (without intervention) are out of this range of values and more closely to the densities observed in NW Spain. The P3 at age 24 produces mean diameter and volume similar to that of the NW Spain yield table (Menéndez-Miguélez et al. 2016) prediction for high density in a medium site index. These yield tables do not apply to the remaining plots due to the differences in density that imply different forestry managements.

Stand density is closely related to the forestry management applied and consequently to the $d g$ obtained. Management models for large roundwood calibers are not intended to maximize total volume production or biomass but individual growth to achieve larger 
diameters. Under this assumption, the productivity obtained so far follows the ones reported by Bourgeois for France and Italy for medium-good sites.

The assessment of the plots is ongoing. The applied silvicultural models converged, in P1, to three final shoots per stool in the last thinning; in P2, to two shoots per stool in the last thinning and in P4, to one shoot per stool at the most. In P4, the final density will only be reached from the next thinning that should occur when height will be around $18 \mathrm{~m}$. The remaining plots will not be subject to further thinning. The reference silvicultural management models proposed by Bourgeois (1992) and Bourgeois et al. (2004), which have been tested for Portuguese site conditions, should be adapted according to the effective number of shoots per hectare, before and after thinning, indicated in Table 1, when applied to Portuguese sweet chestnut coppices or similar.

\section{Volume equations}

Linear models (EVT1-EVT3) presented a slightly better performance than nonlinear models (EVT4-EVT6). The final decision was between EVT2 and EVT1, both using the same explanatory variable, except that EVT2 does not contain an intercept (Table 7). We used the only known published total volume equation for Portuguese chestnut coppices (Fortuna 1969) to analyze mean bias and average error by diameter class $(5 \mathrm{~cm})$ in the fitting dataset and comparing with the candidate equations. The Fortuna (1969) equation showed, in general, an overall overestimation tendency in opposition to the candidate equations. We then calculated the volumes of the four plots for the 2016 measurement using the Fortuna (1969) equation and the candidate equations. Based on this procedure we finally decided to propose the EVT1 model to calculate the stem total volume $(\mathrm{v}=0.0005318+0.00003773$ $\left.\mathrm{d}^{2} \mathrm{~h}\right)$.

Equations of percentage volume as a function of $d i$ presented a slightly inferior performance than equations of percentage volume as a function of $h i$ (Table 7), however, the first equation allows differentiation by categories of roundwood. From the first group, the Matney and Sullivan (1980) equation (EVPD2) is proposed. The final parameterization of the equation is: $\mathrm{R}=1-\left(1-\exp \left(-0.655771 \tan \left(0.854261 \mathrm{~h}^{0.155312}(\mathrm{di} / \mathrm{d})\right)\right)\right)^{2.598471}$.

We used this equation together with the proposed total volume equation to compute, using data from the most recent plot assessment in 2016, the available volumes considering the three major merchantable top diameters $(\mathrm{di}=15 \mathrm{~cm}, 20 \mathrm{~cm}$, and $25 \mathrm{~cm})$. The calculations were done by top diameter classes in each individual plot (silvicultural management model) and the volumes obtained were then expressed as a percentage of total plot volume. The comparison of results in the four plots is presented in Fig. 1. It is clear that the merchantable top diameter volume in P3 (the control without silvicultural intervention) is strongly based in trees from the smallest top diameter classes $(\mathrm{di} \leq 15 \mathrm{~cm})$. In P1 (small diameters) the top diameter classes with most representation is di $15 \mathrm{~cm}$. The major top diameter classes are mainly present in P2 (medium diameters) and P4 (large diameters). However, P4 produces the largest top diameters as expected to obtain roundwood more valuable than the other silvicultural management models. The results are in line with our objectives demonstrating that effective silvicultural management is worth comparing to the traditional one since it promotes the increase of the caliber and quality of sawlogs providing a superior added-value for the mountain economy.

From the second group (merchantable height $h i$ ) the proposed equation is EVPH1 from Cao et al. (1980) whose final parameterization is: $\mathrm{R}=1+\left(-0.66436(\mathrm{~h}-\mathrm{hi})^{2.74570} / \mathrm{h}^{2.59844}\right)$. 
Table 7 Indicators of the performance of total volume equations, percentage volume equations as a function of $d i$ and $h i$, and performance of generalized $\mathrm{H}-\mathrm{D}$ equations

\begin{tabular}{|c|c|c|c|c|c|c|c|c|}
\hline Model & AIC & MPress & MAPress & Press & R2Press & R2Adj & RMSE & QTE \\
\hline \multicolumn{9}{|c|}{ Indicators of the performance of total volume equations } \\
\hline EVT1 & -3007 & 0.00132 & 0.00552 & 0.0639 & 0.879 & 0.980 & 0.0000041 & 0.000183 \\
\hline EVT2 & -3020 & 0.00073 & 0.00563 & 0.0620 & 0.883 & 0.985 & 0.0000044 & 0.000177 \\
\hline EVT3 & -2991 & 0.00154 & 0.00557 & 0.0672 & 0.873 & 0.986 & 0.0000042 & 0.000191 \\
\hline EVT4 & -2983 & 0.00168 & 0.00552 & 0.0687 & 0.870 & 0.979 & 0.0000043 & 0.000195 \\
\hline EVT5 & -2985 & 0.00172 & 0.00549 & 0.0686 & 0.871 & 0.979 & 0.0000042 & 0.000195 \\
\hline EVT6 & -2987 & 0.00115 & 0.00561 & 0.0682 & 0.871 & 0.978 & 0.0000043 & 0.000194 \\
\hline \multicolumn{9}{|c|}{ Indicators of the performance of percentage volume equations as a function of di } \\
\hline EVPD1 & -7657 & 0.00045 & 0.04557 & 5.085 & 0.908 & 0.938 & 0.04823 & 0.003704 \\
\hline EVPD2 & -7925 & -0.00004 & 0.04071 & 4.177 & 0.925 & 0.951 & 0.04322 & 0.003042 \\
\hline EVPD3 & -7305 & -0.00081 & 0.05206 & 6.576 & 0.882 & 0.918 & 0.05504 & 0.004797 \\
\hline EVPD4 & -7919 & -0.00019 & 0.04086 & 4.196 & 0.924 & 0.951 & 0.04336 & 0.003055 \\
\hline EVPD5 & -7584 & -0.00084 & 0.04701 & 5.363 & 0.903 & 0.934 & 0.04972 & 0.003906 \\
\hline \multicolumn{9}{|c|}{ Indicators of the performance of percentage volume equations as a function of hi } \\
\hline EVPH1 & -8793 & 0.00011 & 0.02964 & 2.218 & 0.960 & 0.974 & 0.03139 & 0.001616 \\
\hline EVPH2 & -8789 & 0.00011 & 0.02968 & 2.223 & 0.960 & 0.974 & 0.03142 & 0.001618 \\
\hline EVPH3 & -8577 & 0.00001 & 0.03269 & 2.597 & 0.953 & 0.969 & 0.03440 & 0.001897 \\
\hline EVPH4 & -8516 & -0.00272 & 0.03333 & 2.715 & 0.951 & 0.967 & 0.03509 & 0.001981 \\
\hline EVPH5 & -8642 & -0.00172 & 0.03177 & 2.476 & 0.955 & 0.970 & 0.03351 & 0.001804 \\
\hline \multicolumn{9}{|c|}{ Indicators of the performance of generalized $H-D$ equations } \\
\hline EHG1 & 792 & 0.03932 & 0.89376 & 3646 & 0.882 & 0.882 & 1.156 & 1.335 \\
\hline EHG2 & 638 & 0.02282 & 0.86518 & 3447 & 0.889 & 0.889 & 1.123 & 1.260 \\
\hline EHG3 & 742 & 0.00156 & 0.88035 & 3581 & 0.884 & 0.885 & 1.145 & 1.309 \\
\hline EHG4 & 657 & 0.03390 & 0.87051 & 3472 & 0.888 & 0.888 & 1.127 & 1.269 \\
\hline EHG5 & 659 & 0.02133 & 0.87109 & 3475 & 0.888 & 0.888 & 1.127 & 1.269 \\
\hline
\end{tabular}

Fig. 1 Available estimated volume at age 24 for top diameter (di) $15 \mathrm{~cm}, 20 \mathrm{~cm}$ and $25 \mathrm{~cm}$

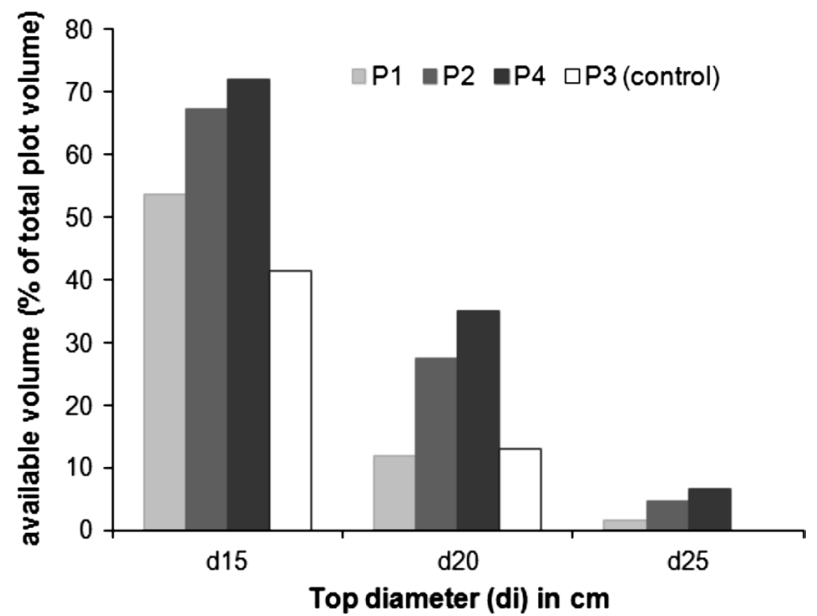




\section{H-D Equations}

EHG2, an adaptation of the Michailoff equation modified by Tomé (1988) showed the best performance among the generalized H-D equations tested (Table 7). The Q-Q plot of studentized residuals from the fit using $n l s$ function did not reveal a substantial departure from normality. Also, no meaningful departure from homoscedasticity was observed from the plot of studentized residuals against fitted values. Nevertheless, the final parameterization of the model was obtained using the gnls function from R package nlme which allowed to model autocorrelation of the residuals due to repeated measurements at the individual level (we used a continuous autoregressive model of order 1 (corCAR1)). We also corrected for a slight deviation from the assumption of the constant variance of residuals using the varPower variance function structure option with a power of hdom in the weights argument of function gnls. Plots of residuals from the generalized nonlinear least squares fit are presented in Fig. 2. The final proposed equation (EHG2) is:

$\mathrm{h}=1.3+(\mathrm{hdom}-1.3) \exp ((-2.4357374-0.2155601 \mathrm{hdom}+0.2913532(\mathrm{Nsh} / 1000))((1 / \mathrm{d})-(1 / \mathrm{ddom})))$.

The study trend of the height growth inside the plots based on the equation EHG2 is shown in Fig. 3. The growth trend shows different patterns related to the silvicultural management practiced in each plot.

The set of proposed equations were constructed with the data that has been successively collected in the described study plots. Future measurements are expected that will allow calibration/improvement of the models as the range of available data will hopefully continue to increase.
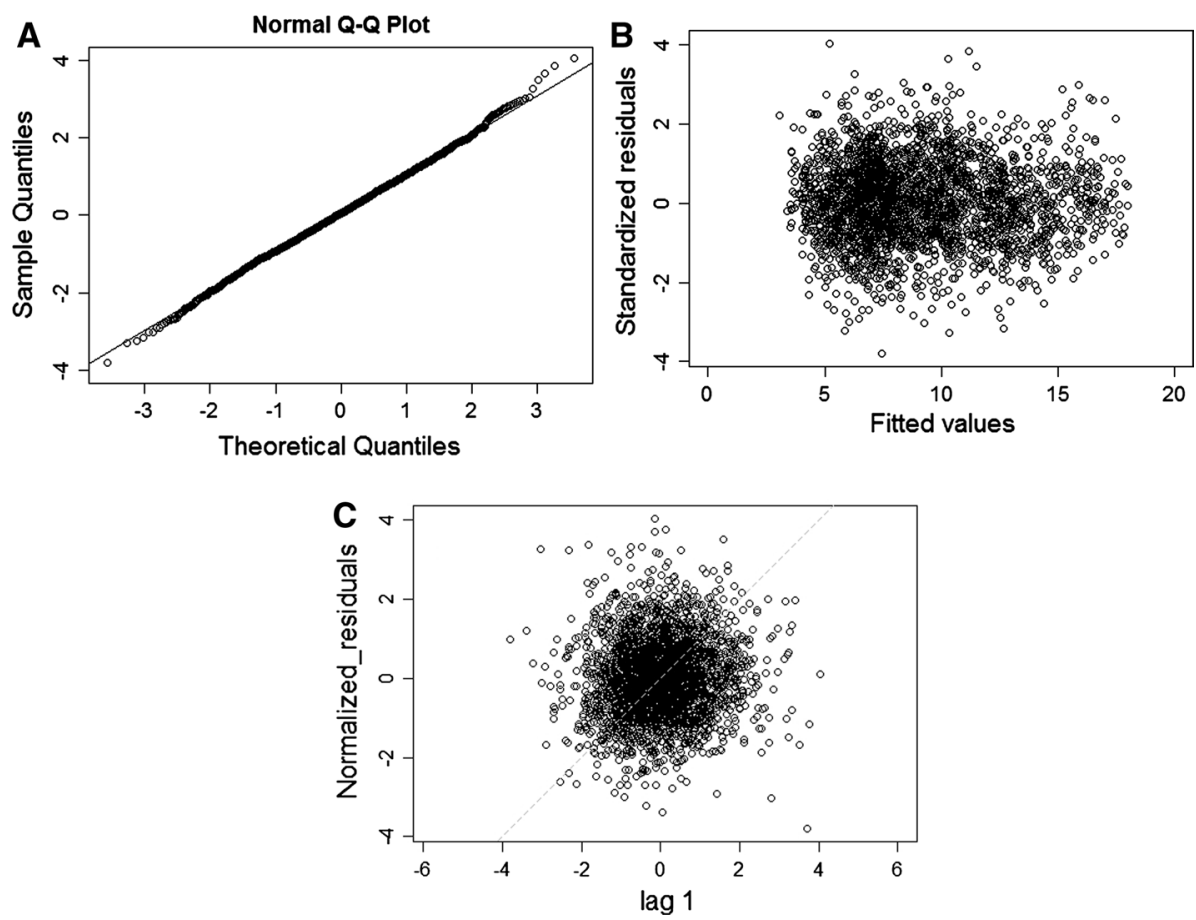

Fig. 2 Q-Q plot of standardized residuals (a); standardized residuals $V s$ fitted values (b); normalized residuals $V$ s its lag 1 values (c) 

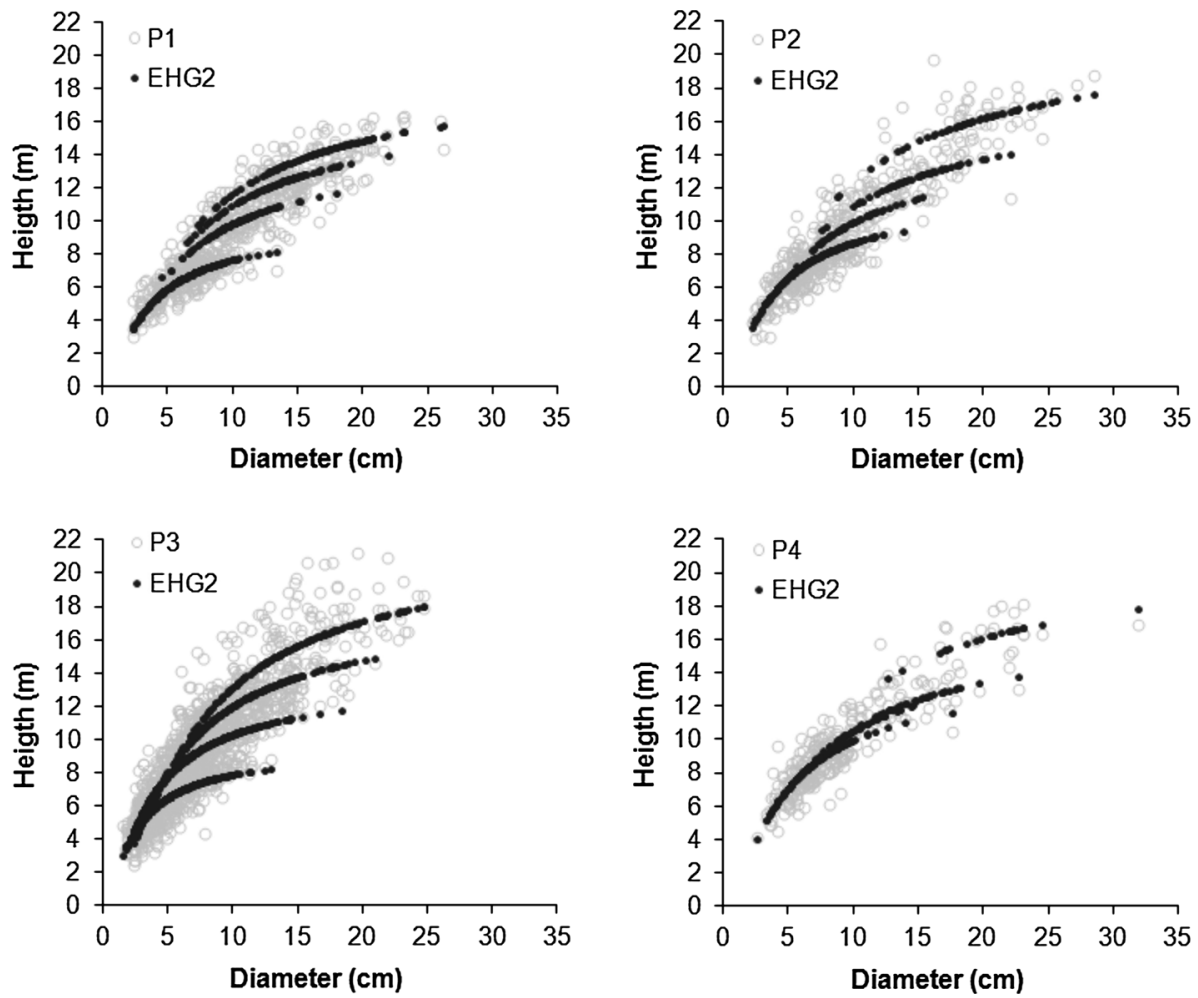

Fig. 3 Estimation trends of $\mathrm{H}$ growth based on selected generalized hypsometric equation superimposed on the H-D data in each plot

\section{Conclusions}

This study has proved that there are advantages for landowners in applying these management models concerning stem quality for saw-timber and sustainability of sweet chestnut coppices.

The quality of the sawlogs is clearly superior to that of the plot without intervention although the dominant trees may have similar growth rates. In the control plot, there is a natural reduction in the number of shoots almost equivalent to that imposed by thinning in P1. Comparing the mean dendrometric values, higher values were observed in plots with the model's application. It is verified that treatment without intervention naturally tends toward the results of the model for small diameters. The results also show that when the roundwood is used for saw-timber, silvicultural intervention is essential. For this purpose, the coppice should be conducted maintaining a relative spacing index in the range $24-32 \%$. Maximizing the quality of roundwood increases the harvest proportion of wood that can be incorporated in long-lived products, a practice that is environmental more sustainable, using only the management residues for bioenergy. This type of forestry management will increase GHG emissions mitigation benefits.

The potential forest residues from thinning that could be directed to bioenergy at age 24 ranges from 59.4 to $98.3 \mathrm{Mg} \mathrm{ha}^{-1}$, dependent on the type of management. 
When coppice is unmanaged and quality does not satisfy uses that lead to carbon storage for longer periods of time, biomass production is a possibility. At age 24, in a $S I_{20}=15 \mathrm{~m}$ the biomass potential produced reaches $148.6 \mathrm{Mg} \mathrm{ha}^{-1}$.

Although the assessment of study plots is still in progress some results are already evident. The P1, model for small diameters (on the inferior boundary of its rotation period) presents a $d g$ of about $17 \mathrm{~cm}$ and $h g$ of $13 \mathrm{~m}$ and is in accordance with the expected values in reference models (mean diameter $14-25 \mathrm{~cm}$ at $25-30$ years). It is possible to produce average diameter sawlogs similar to the reference models in our edaphoclimatic conditions.

The plots submitted to forest management (application of the silvicultural models) undoubtedly give a better result than the control plot without intervention. We can improve the potential of chestnut coppices for sawlogs through silvicultural management, improving the benefits for landowners and contributing to the sustainability of the mountain economy.

Finally, we make available generalized $\mathrm{h}-\mathrm{d}$ and volume equations to monitor and predict the growth and yield trends related to the applied silvicultural management models of sweet chestnut coppices in similar conditions. These equations can be used by forest managers to monitor height, growth and yield in the juvenile phase and first stages of maturity on their chestnut coppices to predict the potential stumpage value to be obtained.

Acknowledgements Conception of the study, data analysis, drafting of the manuscript and critical revision: MSP and LN. Contributed materials: MSP and MLM. Data used in this study was collected with the financial support of the EU project AIR 2-CT94-0905-MEDCOP: Improvement of Coppice Forests in the Mediterranean Region, AGRO Program, Project 267: Sustainable Management of Chestnut Forested Areas in High-Forest and Coppice Systems, and Project PTDC/AGRCFL/68186/Mixed forests: Modeling, dynamics and geographical distribution of productivity and carbon storage in mixed forest ecosystems in Portugal, founded by the Portuguese Science Foundation (FCT) and FEDER-COMPETE Program. The authors wish to thank the availability and cooperation of Forest Services (ICNF) for this study.

\section{References}

Amorini E, Manetti MC (2000) Le fustaie da legno di castagno del Monte Amiata. Ann Ist Sper Selv Arezzo 28:53-61

Assmann E (1961) Waldertargskunde. Bayr. Landw, Müchen

Assmann E (1970) The principles of forest yield study. English transl. S.H. Gardiner, Pergamon Press Ltd., Oxford

Birdsey R, Duffy P, Smyth C, Akurz W, Dugan AJ, Houghton R (2018) Climate, economic, and environmental impacts of producing wood for bioenergy. Environ Res Lett 13:050201

Bourgeois C (1987) Améliorer les taillis de châtaignier. Forêt Entreprise 44:8-15

Bourgeois C (1992) Le châtaignier un arbre, un bois. IDF, 1ère ed., Paris

Bourgeois C, Sevrin E, Lemaire J (2004) Le châtaignier un arbre, un bois. IDF, 2eme ed., Paris

Burkhart HE (1977) Cubic-foot volume of loblolly pine to any merchantable top limit. South J Appl For $1: 7-9$

Cao QV, Burkhart HE, Max TA (1980) Evaluation of two methods for cubic-volume prediction of loblolly pine to any merchantable limit. For Sci 26(1):71-80

Cutini A (2001) New management options in chestnut coppices: an evaluation on ecological bases. For Ecol Manag 141:165-174

Deusen PCV, Sullivan AD, Matney TG (1981) A prediction system for cubic foot volume of loblolly pine applicable through much of its range. South J Appl For 5:186-189

Fortuna ERM (1969) Tabelas de volume para o castanheiro bravo. Estudos e Informação 245, Secretaria de Estado da Agricultura, DGSFA, Lisboa, Portugal

Fuller RJ, Moreton BD (1987) Breeding bird population of Kentish sweet chestnut (Castanea sativa) coppice in relation to age and structure of the coppice. J Appl Ecol 24:13-27

Geraldes SAA (2011) Avaliação de modelos silvícolas e validação de ferramentas de gestão para o castanheiro em Trás-os-Montes. Bragança: Instituto Politécnico de Bragança, Escola Superior Agrária. Dissertation, Mestrado em Gestão de Recursos Florestais 
Harrison W, Burk T, Beck D (1986) Individual tree basal area increment and total height equations for Appalachian mixed hardwoods after thinning. South J Appl For 10:99-104

Honer TG (1965) A new total cubic-foot volume function. For Chron 41:476-493

Huber PJ (1964) Robust estimation of a location parameter. Ann Math Stat 35:73-101

Iamshchikov V (2017) Evaluation of management models in a trial of Castanea sativa Mill. coppice in northern Portugal. Dissertation, Instituto Politécnico de Bragança, ESA, Bragança, Portugal

Icnf IP (2013) IFN6-Áreas dos usos do solo e das espécies florestais de Portugal continental. Resultados preliminares. Instituto da Conservação da Natureza e das Florestas, Lisboa

INMG (1991) O clima de Portugal. Fascículo XLIX, vol. 3, 3a Região

Kraft G (1884) Beiträge zur Lehre von den Durchforstungen, Schlagstellungen und Lichtungshieben. Klindworth's Verlag, Hannover

Luís JFS, Monteiro ML (1998) Dynamics of a broadleaved (Castanea sativa) conifer (Pseudotsuga menziesii) mixed stands in Northern Portugal. For Ecol Manag 107:183-190

Matney TG, Sullivan AD (1980) Estimation of merchantable volume and height of natural grown slash pine trees. Arid land resources inventories workshop, La Paz, Mexico

Menéndez-Miguélez M, Álvarez-Álvarez P, Majada J, Canga E (2015) Effects of soil nutrients and environmental factors on site productivity in Castanea sativa Mill. coppice stands in NW Spain. New For 46:217-233

Menéndez-Miguélez M, Álvarez-Álvarez P, Majada J, Canga E (2016) Management tools for Castanea sativa coppice stands in northwestern Spain. Bosque 37(1):119-133

Monteiro ML, Patrício MS (1996) O castanheiro: modelos de gestão. Revista Florestal ix(4):51-56

Myers RH (1986) Classical and modern regression with applications. Duxbury Press, Boston

Ogaya N (1968) Kubierungsformeln und Bestandesmassenformeln. Dissertation, Univ. Freiburg I. Br

Parresol BR, Hotvedt JE, Cao QV (1987) A volume and taper prediction system for bald cypress. Can J For Res 17:250-259

Patrício MS (1996) Análise do crescimento da fase juvenil de um ensaio de densidade de varas numa talhadia de castanheiro. Dissertation, Universidade Técnica de Lisboa, Instituto Superior de Agronomia, Lisboa

Patrício MS (2006) Análise da Potencialidade Produtiva do Castanheiro em Portugal. Dissertation, Universidade Técnica de Lisboa, Instituto Superior de Agronomia, Lisboa

Patrício MS, Nunes L (2017) Density management diagrams for sweet chestnut high-forest stands in Portugal. iForest 10:865-870

Patrício MS, Monteiro ML, Nunes LF, Mesquita S, Beito S, Casado J, Guerra H (2005) Management models evaluation of a Castanea sativa coppice in the northeast of Portugal. Acta Hort 693:721-726

Patrício MS, Geraldes S, Nunes LF, Monteiro ML (2009) Sustainable management models applied to chestnut coppice in the north-east of Portugal. FAO-XIII world forest congress, 16-23 October, Buenos Aires

R Core Team (2018) R: a language and environment for statistical computing. R Foundation for Statistical Computing, Vienna

Reed DD, Green EJ (1984) Compatible stem taper and volume ratio equations. For Sci 30(4):977-990

Romane F, Houssard C (1995) The sustainability of chestnut ecosystem. In: Romane F (ed) Sustainability of mediterranean ecosystems. Case study of the chestnut forest. European commission, Brussels, ecosystem research report no. 19, pp 173-176

Schumacher FX, Hall F (1933) Logarithmic expression of timber-tree volume. J Agric Res 47:719-734

Spurr SH (1952) Forest inventory. Ronald Press, New York

Tomé M (1988) Modelação do crescimento da árvore individual em povoamentos de Eucalyptus globulus Labill. (1a rotação) Região Centro de Portugal. Dissertation, UTL-ISA, Lisboa

Publisher's Note Springer Nature remains neutral with regard to jurisdictional claims in published maps and institutional affiliations. 